\title{
Photocurrent and Photoluminescence Investigations of GaInNAs and GaInNAs(Sb) Quantum Wells Grown by Molecular Beam Epitaxy
}

\author{
${ }^{1}$ S. Ben Bouzid, ${ }^{1}$ F. Bousbih, ${ }^{1}$ A. Hamdouni, ${ }^{1}$ R. Chtourou, ${ }^{2}$ J.C. Harmand and ${ }^{2}$ P. Voisin \\ ${ }^{1}$ Laboratoire de Photovoltaïque et des Semiconducteurs, Institut National de Recherche Scientifique et \\ Technique, BP.95, Hammam-Lif 2050, Tunisia, Tunis \\ ${ }^{2}$ Laboratoire de Photonique et de Nanostructures, CNRS, Route de Nozay, 91460 Marcoussis, France
}

\begin{abstract}
We have investigated photocurrent (PC) and photoluminescence (PL) in sequentially grown GaInNAs/GaAs and GaInNAs(Sb)/GaAsSbN quantum wells. Photocurrent transitions are analyzed by theoretical calculations using envelope function formalism taking into account the strain effect and the strong coupling between nitrogen localized state and the GaInAs band gap. The results are consistent with a type I band alignment and a conduction band offset ratio of about $80 \%$. Additionally, our results suggest an increase of the electron effective mass by as much as $0.035 \mathrm{~m}_{0}$ resulting from the flattening of the conduction band under nitrogen effect. The temperature evolution of the PL peak energy and the integrated PL intensity of GaInNAsSb QW show evidence of strong localization of carriers. Both, the high delocalization temperature, in the $230 \mathrm{~K}$ range and the strong shift between the PC and PL spectra of GaInNAsSb QW, indicate the presence of deeper localized states as compared to that in the GaInNAs QW.
\end{abstract}

Key words: GaInNAs, GaInNAsSb, photocurrent, photoluminescence, molecular beam epitaxy

\section{INTRODUCTION}

Proposed by Kodow et $a l^{[1]}$, InGaAsN opens up new opportunities to realize low-cost, high performance $1.3 \mu \mathrm{m}$ emitting semiconductor diode lasers grown on GaAs substrates. With intensive research effort, high performance $1.3 \mu \mathrm{m}$ emitting InGaAsN quantum well (QW) lasers have been successfully reported using both molecular beam epitaxy (MBE) ${ }^{[2,3]}$ and Metalorganic Chemical Vapor Deposition MOCVD growth ${ }^{[4,5]}$. Optimized structures exhibit reduced threshold current density and lower temperature sensitivity as compared to conventional InP-based $1.3 \mu \mathrm{m}$ emitting lasers. One challenging goal remaining is to extend the emission wavelength beyond $1.3 \mu \mathrm{m}$, while maintaining optical material quality for the realization of longer wavelength, high-performance, GaAs based devices. Wang et $a l$. found that adding antimony as a surfactant during GaInNAs growth allowed longer wavelength devices ${ }^{[6]}$. From $\boldsymbol{k} \cdot \boldsymbol{p}$ methods, it was theoretically predicted that nitride-antimonide alloys should posses similar bowing to the nitride-arsenide ${ }^{[7]}$. This was experimentally validated when it was found that cracked antimony incorporates into the crystal ${ }^{[8,9]}$, further redshifting emission and allowing the demonstration of lasers operating in pulsed mode out to $1.49 \mu \mathrm{m}^{[10]}$. In this work, we used an experimental technique, the photocurrent (PC) together with photoluminescence $(\mathrm{PL})$ techniques to investigate the electronic and optical properties of GaInNAs/GaAs quantum well and compared the results with those obtained from a sequentially grown GaInNAsSb/GaAsSbN quantum well.

\section{MATERIALS AND METHODS}

In this study, two quantum wells (QWs) were grown by molecular beam epitaxy on an n-type GaAs (100) substrate using a radio frequency (rf) $\mathrm{N}$ radical beam source. The active region consists of $7 \mathrm{~nm}$ $\mathrm{GaIn}_{0.37} \mathrm{~N}_{0.013} \mathrm{As}$ or $\mathrm{GaIn}_{0.4} \mathrm{~N}_{0.01} \mathrm{AsSb}_{0.015}$ quantum wells sandwiched between $100 \mathrm{~nm}$ undoped GaAs waveguide layers. The GaInNAsSb single $\mathrm{QW}$ is surrounded by $\mathrm{GaN}_{0.01} \mathrm{AsSb}_{0.015}$ barriers. A $1.5 \mu \mathrm{m}$ Si- doped $\left(7 \times 10^{17}\right)$ n-type $\mathrm{Al}_{0.8} \mathrm{Ga}_{0.2} \mathrm{As}$ cladding layers was grown between the $n+-G a A s$ buffer layer $(0.2 \mu \mathrm{m})$ and the active layer. A $1.5 \mu \mathrm{m}$ Be-doped $\left(5 \times 10^{17}\right)$ p-type $\mathrm{Al}_{0.8} \mathrm{Ga}_{0.2} \mathrm{As}$ cladding layers followed the active layer. Conventional InZn metallization was used for the p-type contact. The growth temperature for the QWs, the GaAs waveguide layer and $\mathrm{AlGaAs}$ cladding layer were $400,510,550^{\circ} \mathrm{C}$, respectively. To determine the $\mathrm{N}$ and In mole fractions, both X-ray diffraction and pre-calibrated PL investigations of InGaAs structures were performed.

The PC spectra were performed using a halogen lamp dispersed by a $0.25-\mathrm{m}$ Jobin-Yvon monochromator. The chopped monochromatic light was incident on the top of the sample and the capacitiveley

Corresponding Author: S.Ben Bouzid, Laboratoire de Photovoltaïque et des Semiconducteurs, Institut National de Recherche Scientifique et Technique, BP.95, Hammam-Lif 2050, Tunisia, Tunis, Tel: 0021671929841 , Fax: 0021671430934 
coupled photoresponse signal was obtained by measuring the open circuit voltage $\left(\mathrm{V}_{\mathrm{oc}}\right)$ using the lock -in amplifier. The PL measurements were carried out using a variable temperature $(10-300 \mathrm{~K})$ close-cycle cryostat under the excitation of $514.5 \mathrm{~nm}$ line of an Argon ion $\mathrm{Ar}^{+}$laser. The signal was detected through a $0.25-\mathrm{m}$ Jobin-Yvon monochromator and by a GaInAs photodiode associated with a standard lock-in technique.

\section{RESULTS AND DISCUSSION}

Room temperature photocurrent spectra of GaInNAs and GaInNAsSb QWs are shown in Fig. 1. We note that photocurrent spectra of the two samples are formed by well-defined absorption steps and the incorporation of $\mathrm{Sb}$ red shifts the fundamental gap to $850 \mathrm{meV}$. The arrows show the calculated transitions using the nominal thickness, as discussed below. The confined energies of the electrons, heavy and light holes are calculated using the envelope function formalism. The unstrained band gap energy $\mathrm{E}_{\mathrm{g}}^{\mathrm{ust}}$ of $\mathrm{III}(\mathrm{Ga}, \mathrm{In})-\mathrm{V}(\mathrm{As}, \mathrm{Sb})-\mathrm{N}$ layer is determined using the Band Anticrossing Model (BAC $)^{[11]}$ and the strained band gap energy $E_{\mathrm{e}-\mathrm{hh}(\mathrm{lh})}^{\mathrm{st}}(\mathrm{III}-\mathrm{V}-\mathrm{N})$ between the electron and the heavy (light) hole bands is determined taking into account the hydrostatic and shear components of the strain, given by:

$$
\begin{aligned}
& \mathrm{E}_{\mathrm{e}-\mathrm{hh}}^{\mathrm{st}}(\mathrm{III}-\mathrm{V}-\mathrm{N})=\mathrm{E}_{\mathrm{g}}^{\mathrm{ust}}(\mathrm{III}-\mathrm{V}-\mathrm{N})+\mathrm{E}_{\mathrm{hyd}}+\mathrm{E}_{\mathrm{sh}} \\
& \mathrm{E}_{\mathrm{e}-\mathrm{hh}}^{\mathrm{st}}(\mathrm{III}-\mathrm{V}-\mathrm{N})=\mathrm{E}_{\mathrm{e}-\mathrm{hh}}^{\mathrm{st}}(\mathrm{III}-\mathrm{V}-\mathrm{N}) \\
& \left.-1.5 \mathrm{E}_{\mathrm{sh}}+0.5 \Delta_{\mathrm{so}} \mid 1-\sqrt{1+2 \mathrm{E}_{\mathrm{sh}} / \Delta_{\mathrm{so}}+9 \mathrm{E}_{\mathrm{sh}}^{2} / \Delta_{\mathrm{so}}^{2}}\right\rfloor \\
& \mathrm{E}_{\mathrm{hyd}}=\left[2(\mathrm{p}+\Delta \mathrm{p})\left(\mathrm{C}_{11}-\mathrm{C}_{12}\right) / \mathrm{C}_{11} \mid \varepsilon\right. \\
& \mathrm{E}_{\mathrm{sh}}=\left[-\mathrm{q}\left(\mathrm{C}_{11}+2 \mathrm{C}_{12}\right) / \mathrm{C}_{11} \mid \varepsilon\right.
\end{aligned}
$$

Where, $\mathrm{p}$ and $\mathrm{q}$ are respectively the hydrostatic and shear deformation potentials and $\mathrm{C}_{\mathrm{ij}}$ the elastic constants in (In, Ga)As system. $\Delta_{\text {so }}$ is the spin-orbit splitting which is independent of nitrogen content ${ }^{[12]} . \Delta_{p}$ is the shear deformation potential term correction due to $\mathrm{N}$ and $\mathrm{Sb}$ in III-V materials. $\varepsilon$ is relative strain in the plane direction. The electron effective mass in the III$\mathrm{V}-\mathrm{N}$ layer is taken as:

$$
\mathrm{m}_{\mathrm{e}}(\mathrm{III}-\mathrm{V}-\mathrm{N})=\mathrm{m}_{\mathrm{e}}(\mathrm{III}-\mathrm{V})+\Delta \mathrm{m}_{\mathrm{e}}
$$

Where, $m_{e}(I I I-V)$ is the electron effective mass in III-V material and $\Delta \mathrm{m}_{\mathrm{e}}$ is the electron effective mass term correction resulting from the flattening of the conduction band under nitrogen effect. The strained conduction band offset used in our calculation is about
$80 \%$ of the strained heavy hole-electron bandgap difference; this value is the same as for GaInNAs/GaAs QWs with comparable indium and nitrogen contents ${ }^{[13]}$. Figure 2 shows GaInNAs/GaAs QWs calculated transitions energies plotted as a function of the electron effective mass correction for different $\Delta \mathrm{p}$ shear terms correction. Observed transitions energies are indicated as dark squares. A reasonable agreement is found for the $\mathrm{E}_{1}-\mathrm{H}_{1}, \mathrm{E}_{1}-\mathrm{L}_{1}$ and $\mathrm{E}_{2}-\mathrm{H}_{2}$ data using $\Delta \mathrm{p} / \mathrm{p}=0.11$ and $\Delta \mathrm{m}_{\mathrm{e}}=0.035 \quad \mathrm{~m}_{0}$. The $\mathrm{E}_{1}-\mathrm{H}_{1}$ and $\mathrm{E}_{1}-\mathrm{L}_{1}$ measured transitions of GaInNAs(Sb)/GaAsSbN SQW are in agreement with the theoretical fit for $\Delta \mathrm{p} / \mathrm{p}=0.3$ and $\Delta \mathrm{m}_{\mathrm{e}}=0.035 \mathrm{~m}_{0}$. We have plotted in Fig. 3 the band-edge profiles of GaInNAs/GaAs and GaInNAs(Sb)/GaAsSbN QWs showing the type I band alignment. We note that the incorporation of $\mathrm{Sb}$ in GaInNAsSb/GaAsSbN have reduced the fundamental gap energy and the electron potential depth from 418 $\mathrm{meV}$ to $340 \mathrm{meV}$ by comparison with GaInNAs/GaAs QWs.

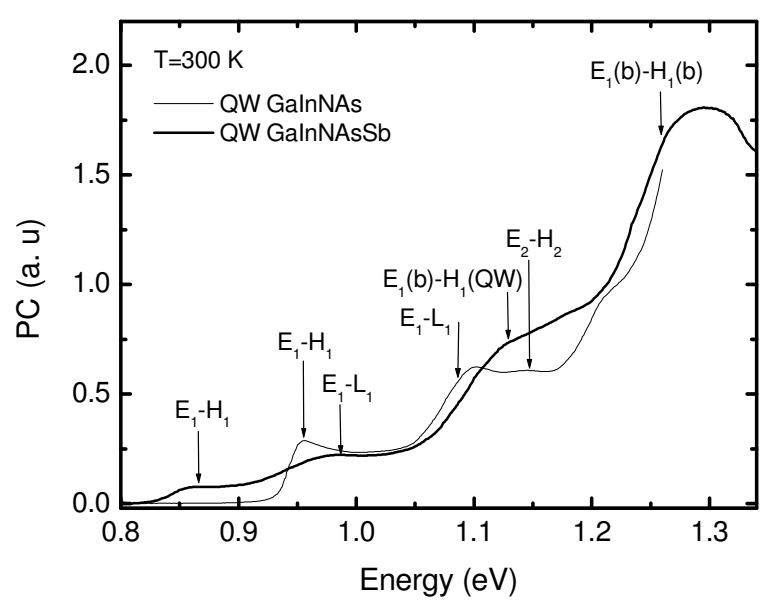

Fig. 1: Room temperature photocurrent spectra of GaInNAs and GaInNAsSb quantum wells

PL spectra of GaInNAs and GaInNAsSb QWs are shown, respectively, in Fig. $4 \mathrm{a}$ and $\mathrm{b}$ at different temperatures. We note that from 300 to $10 \mathrm{~K}$, the PL peak energy increases from 0.935 to $0.977 \mathrm{eV}$ for GaInNAs and from 0.866 to $0.913 \mathrm{eV}$ for GaInNAsSb QWs. The redshift shift $\Delta \mathrm{E}$ between $10 \mathrm{~K}$ and $300 \mathrm{~K}$ is noticeably lower for GaInNAsSb QW (47 meV) than for GaInNAs QW (61 meV). To clarify this point, we have reported in Fig. 5 the temperature dependence of the PL peak energy. The $\mathrm{E}_{1}-\mathrm{H}_{1}$ energy dependence with temperature measured by $\mathrm{PC}$ in the two samples is also shown. The dashed lines are the fits using Bose Einstein $\operatorname{model}^{[14]}$ :

$$
\mathrm{E}_{g}(\mathrm{~T})=\mathrm{E}_{\mathrm{B}}-\mathrm{a}\left[\frac{2}{\exp (\theta / \mathrm{T})-1}+1\right]+\alpha \mathrm{K}_{\mathrm{B}} \mathrm{T}
$$




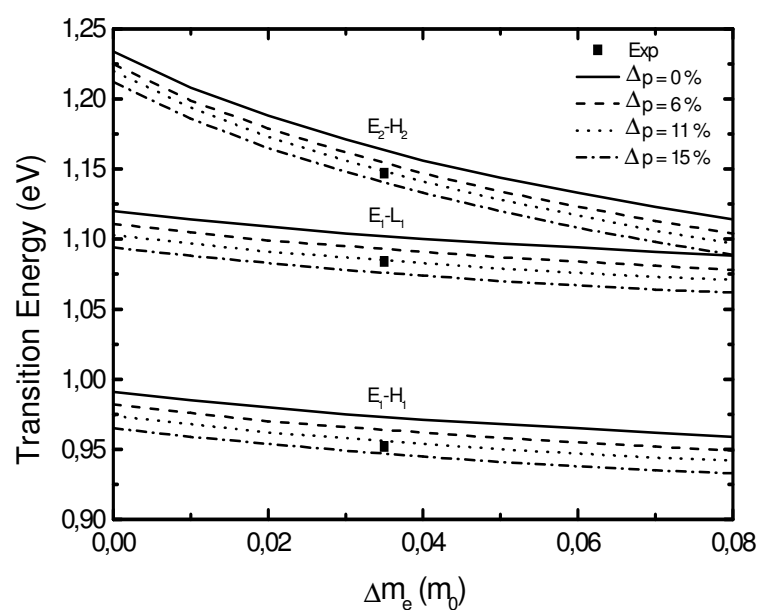

Fig. 2: Room temperature transition energies of GaInNAs as function of the electron effective mass term correction with the theoretical fit (solid and dashed lines) for different $\Delta \mathrm{p}$ shear deformation potential term correction
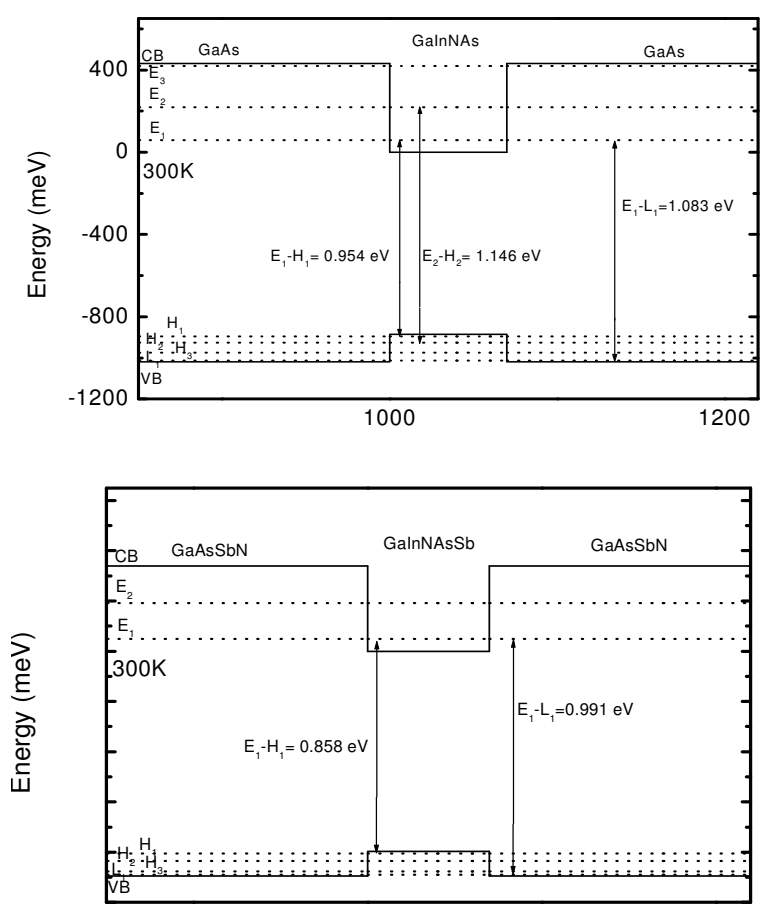

Fig. 3: Room temperature band-edge profiles for GaInNAs and GaInNAsSb quantum wells

Where, $\left(\mathrm{E}_{\mathrm{B}}-\mathrm{a}\right)$ is the transition energy at $0 \mathrm{~K}$, a is the electron phonon interaction strength and $\theta$ is related to the average phonon energy. $\alpha$ is the parameter reflecting the shape of the density of states which is assumed to be about 0.5 here and $\mathrm{K}_{\mathrm{B}}$ is the Boltzmann constant. It is shown that the temperature dependence of PC peak energy can be fitted well by equation (5). For GaInNAs and GaInNAsSb QWs, the optimum fit parameters a and $\theta$ are, respectively equal to 128,97 $\mathrm{meV}$ and $410,340 \mathrm{~K}$. We note that both the electron-
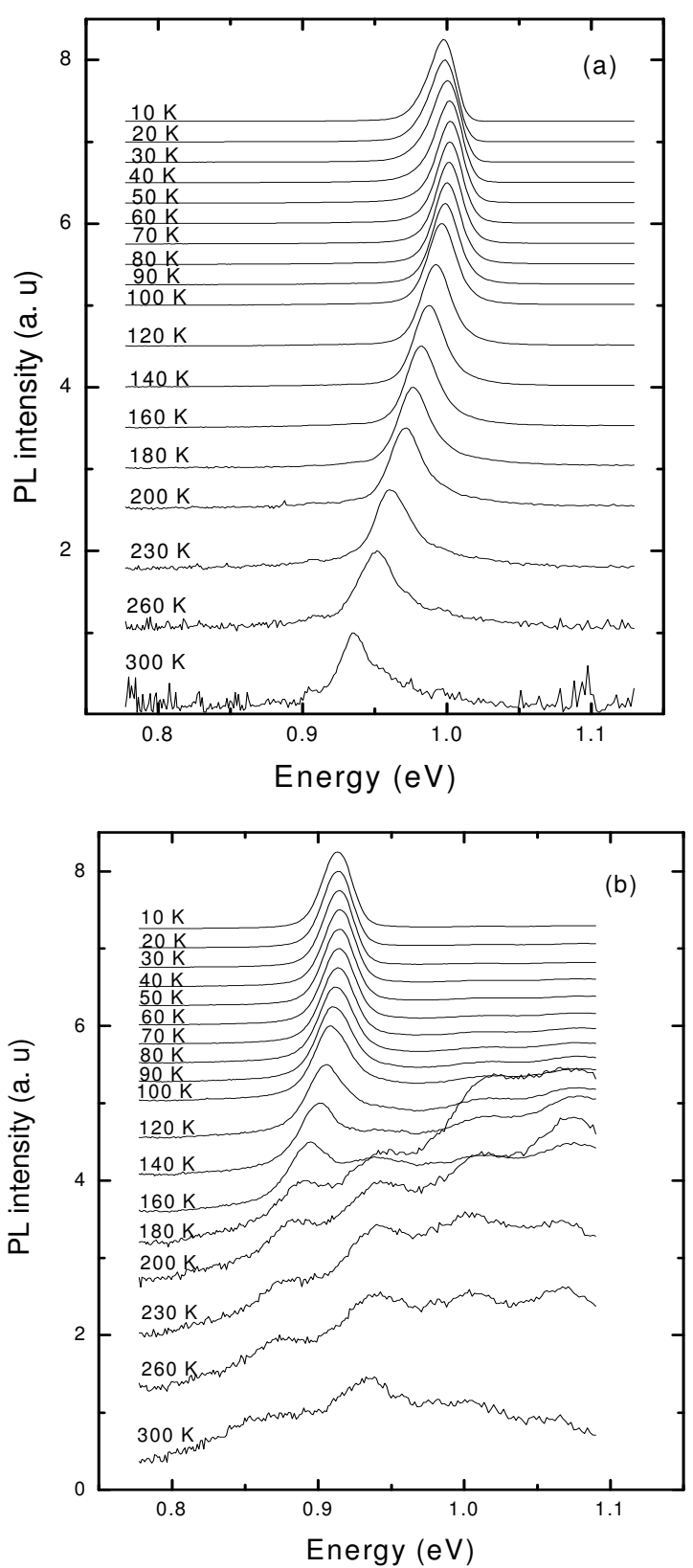

Fig. 4: (a) PL spectra of GaInNAs and (b) GaInNAsSb quantum wells at various temperatures

phonon interaction strength and the average phonon energy decrease with decreasing the nitrogen content from $1.3 \%$ in GaInNAs to $1 \%$ in GaInNAsSb QWs. We have noted that the measured electron-phonon interaction strengths are in agreement with that given by $\mathrm{H}$. Yaguchi et $a l^{[15]}$ in GaAsN layers with comparable nitrogen compositions. In additon, the evolution of the PL peak energy of GaInNAs QW (closed circles) as function of temperature is the same as that of the $\mathrm{E}_{1}-\mathrm{H}_{1}$ transition (open circles), except at low temperature $(10 \mathrm{~K})$ when the PL peak energy is situated at about $13 \mathrm{meV}$ below the $\mathrm{E}_{1}-\mathrm{H}_{1}$ energy. In contrast, the temperature dependence of the PL peak 

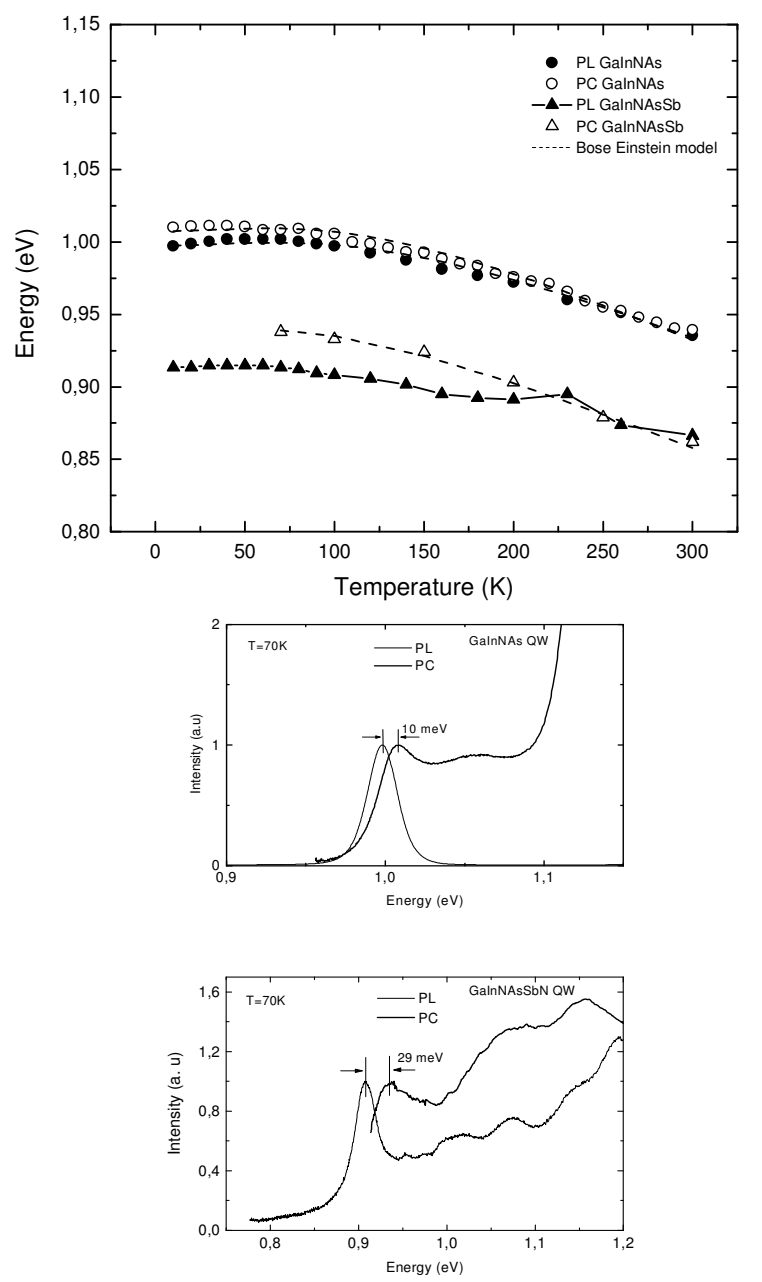

Fig. 5: PL temperature dependence of the emission peak of the GaInNAs (closed circles) and of the GaInNAsSb (closed triangles) QWs. Solid line is a guide to the eyes. Open circles and open triangles represent the $\mathrm{E}_{1}-\mathrm{H}_{1}$ energies of the GaInNAs and GaInNAsSb QWs respectively. The dashed line is a Bose Einstein fit to the PL and PC measurements of the two QWs. The PC and PL Spectra of the two QWs at 70K are shown in the inset

energy of GaInNAsSb QW have an anomalous behaviour, the so-called inverted $\mathrm{S}$ shape behavior indicating a transition between recombinaison from localized and delocalized states. The anomalous temperature induced shift of the emission energy has already been observed by other groups in $\mathrm{N}$ containing III-V alloys ${ }^{[16-19]}$ and it was attributed to localized exciton emission. Between 8 and $160 \mathrm{~K}$ a redshif appears and is believed to be a result of exciton trapping into lower energy localized states. In this region the excitons acquire thermal energy as the temperature increases allowing them to overcome small potential barriers and fall into the lower lying states. However, when the temperature reaches $160 \mathrm{~K}$,
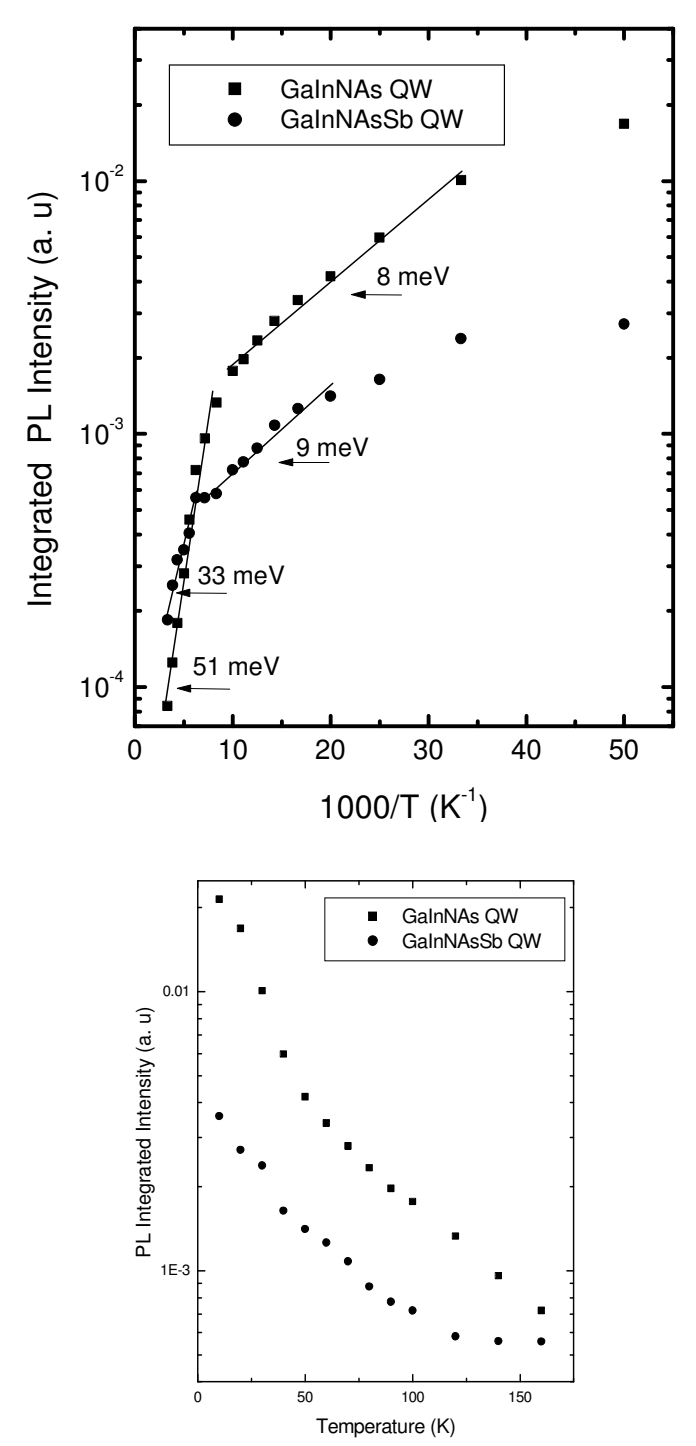

Fig. 6: Integrated PL intensity (log scale) plotted as a function of reciprocal temperature for GaInNAs (closed square) and GaInNAsSb (closed circle) quantum wells

excitons in shallow localized states acquire sufficient thermal energy to become delocalized. As more and more excitons become delocalized, the resulting emission is blue-shifted until the system become fully delocalized at the delocalized temperature about $230 \mathrm{~K}$. Finally excitons are completely delocalized and the PL peak energy is mainly determined by the behaviour of the bandgap as verified by PC measurements. This Sshape explains why the shift between 10 and $300 \mathrm{~K}$, which is directly seen in Fig. 4, is lower for GaInNAsSb QW than for GaInNAs. We show in the inset of Fig. 5 the PC and PL Spectra of the two QWs at $70 \mathrm{~K}$. The strong energy shift between $\mathrm{E}_{1}-\mathrm{H}_{1}$ and the PL peak for GaInNAsSb $(29 \mathrm{meV})$ compared to that of GaInNAs QW (10 meV) shows a high density of possibly deep localizing potentiel wells. This can be 
explained probably by the fact that when $\mathrm{Sb}$ atoms are incorporated into GaInNAs, the density of $\mathrm{N}$ clusters and the related potentiel fluctuation are increased due to the diminution of the preferable formation of $\mathrm{N}$-In covalents bonds. In fact, In-N bonds help $\mathrm{N}$ clusters to segregate from lattice and reduce the azote induced potentiel fluctuations ${ }^{[20]}$.

Temperature dependence of $\mathrm{PC}$ is shown in the inset of Fig. 6. The PL intensity of GaInNAs and GaInNAsSb QWs decreases rapidly with increasing temperature. In order to analyse temperature dependence of PL, we plotted the logarithm of the integrated PL intensity as function of reciprocal temperature as shown in Fig. 6. The samples show a remarkable behavior characterized by two temperatures regimes both of which obey an Arrhenius relationship. The low temperature activation energy $E_{a 1}$ derived by the linear part of the plot, was found to be $9 \mathrm{meV}$ and 8 meV repectively for GaInNAsSb and GaInNAs QWs; and the high temperature activation energy $E_{a 2}$ was found to be $33 \mathrm{meV}$ and $51 \mathrm{meV}$ repectively for GaInNAsSb and GaInNAs QWs. Like other works, the activation energies increase with the azote incorporation $^{[21,22]}$. For an alternative explanation, $\mathrm{E}_{\mathrm{a} 1}$ is related to the ionization of impurety bound excitons. On the other hand, the deep traps are the most likely cause of the thermal activation energy $\mathrm{E}_{\mathrm{a} 2}$.

\section{CONCLUSION}

Optical properties of GaInNAs and GaInNAsSb QWs have been investigated by photocurrent and photoluminescence spectroscopy. In the case of PC measurements, we have observed optical transitions in the two samples. Based on calculations from experimental data, we have found an increase of the electron effective mass by as much as $0.035 \mathrm{~m}_{0}$ and the conduction band offset is about $80 \%$. Morover, we find less temperature dependence of the PL energy of the sample containing antimony due to the deeper localized states. This behaviour can be explained probably by the fact that when $\mathrm{Sb}$ atoms are incorporated into GaInNAs, the density of $\mathrm{N}$ clusters and the related potentiel fluctuation are increased due to the diminution of the preferable formation of $\mathrm{N}$-In covalent bonds

\section{REFERENCES}

1. Kondow, M., K. Uomi, A. Niwa, T. Kitatani, S. Watahiki and Y. Yazawa, 1996. Jpn. J. Appl. Phys., 33: 1273.

2. Livshits, D.A., A.Y. Egorov and H. Riechert, 2000. Electron. Lett., 36: 1381.
3. Fisher, M., D. Gollub, M. Reinhardt, M. kamp and A. Forchel, 2003. J. Crystal Growth, 251: 353.

4. Takeuchi, T., Y.L. Chang, M. Leary, A. Tandon, H.C. Luan, D. Bour, S. Corzine, R. Twist and M. Tan, 2002. Electron. Lett., 38: 1438.

5. Kawaguchi, M., T. Miyamoto, E. Gouardes, D. Schlenker, T. Kondo, F. Koyama and K. Iga, 2001. Jpn. J. Appl. Phys. 2-Lett., 40: L744.

6. Yang, X., M.J. Jurkovic, J.B. Heroux and W.I. Wang, 1999. Appl. Phys. Lett., 75: 178.

7. Murdin, B.N., A.R. Adams, P. Murzyn, C.R. Pidgeon, I.V. Bradley, J.P.R. Wells, Y.H. Matsuda, N. Miura, T. Burke and A.D. Johnson, 2002. Appl. Phys. Lett., 81: 256-258.

8. Shimizu, H., K. Kumada, S. Uchiyama and A. Kasukawa, 2000. Electron. Lett., 36: 1701-1703.

9. Gambin, V., W. Ha, M. Wistey, H. Yuen, S.R. Bank, S.M. Kim, J.S. Harris Jr., 2002. IEEE J. Select. Topics Quantum Electron, 8: 795-800.

10. Ha, W., V. Gambin, S. Bank, M. Wistey, H. Yuen, S. Kim and J.S. Harris Jr., 2002. IEEE J. Quantum Electron, 38: 1260-1267.

11. Shan, W., W. Walukiewicz, J.W. Ager III, E.E. Haller, J.F. Geisz, D.J. Friedman, J.M. Olson, S.R. Kurtz, 1999. Phys. Rev. Lett., 82: 1221-1224.

12. Perkins, J.D., A. Mascarenhas, Y. Zhang, J.F. Geisz, D.J. Friedman, J.M. Olson, S.R. Kurtz, 1999. Phys. Rev. Lett., 82: 3312-3315.

13. Hetterich, M., M.D. Dawson, A. Yu. Egorov, D. Bernklau and H. Riechert, 2000. Appl. Phys. Lett., 76: 1030-1032.

14. Lautenschlager, P., M. Garriga, S. Logothetidis and M. Cardonna, 1987. Phys. Rev.B., 35: 9174.

15. Yaguchi, H., S. Kikuchi, Y. Hijikata, S. Yoshida, D. Aoki and K. Onabe, 2001. Phys. Stat. Sol.(b), 228: 273-277.

16. Grenouillet, L., C. Bru. Chavalier, G. Guillot, P. Gilet, P. Duvaut, C. Vannuffel, A. Million and A. Chenevas-Paule, 2000. Appl. Phys. Lett., 76: 2241.

17. Pinault, M.A. and E. Tournié, 2001. Appl. Phys. Lett., 78: 1562.

18. Cho, Y.H., G.H. Gainer, A.J. Fischer, J.J. Song, S. Keller, U. K. Mishra, et al., 1998. Appl. Phys. Lett., 73: 1370.

19. Hoffmann, A., R. Heitz, A. Kaschner, T. Luttgert, H. Born, A.Y. Egorov and H. Riechert, 2002. Mater. Sci. Engg. B., 93: 55-59.

20. Sun, B.Q., D.S. Jiang, Z. Pan, L.H. Li and R.H. Wu, 2000. Appl. Phys. Lett., 77 : 4148.

21. Zhou, W., S.J. Chua, J.R. Dong and J.H. Teng, 2002. J. Cryst. Growth., 242 : 15-19.

22. Sanorpim, S., F. Nakajima, R. Katayama, K. Onabe and Y. Shiraki, 2003. Mat. Res. Soc. Symp. Proc., 744 : M10.9.1. 